E International

Understanding Urban Travel Behaviour by Gender for Efficient and Equitable Transport Policies

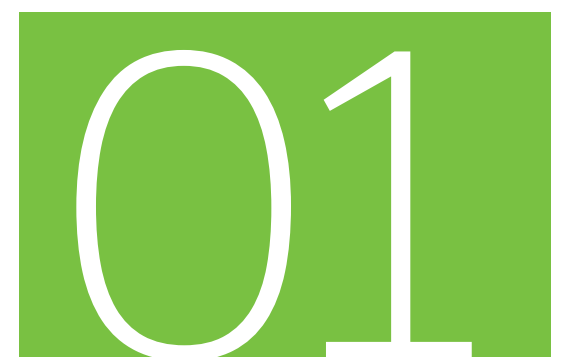

Discussion Paper 2018 • 01

Wei-Shiuen $\mathrm{Ng}$ and Ashley Acker

International Transport Forum, Paris, France 


\section{E International Transport Forum}

\section{Understanding Urban Travel Behaviour by Gender for Efficient and Equitable Transport Policies}

Discussion Paper No. 2018-01

Wei-Shiuen Ng and Ashley Acker International Transport Forum, Paris, France

February 2018 


\title{
The International Transport Forum
}

The International Transport Forum is an intergovernmental organisation with 59 member countries. It acts as a think tank for transport policy and organises the Annual Summit of transport ministers. ITF is the only global body that covers all transport modes. The ITF is politically autonomous and administratively integrated with the OECD.

The ITF works for transport policies that improve peoples' lives. Our mission is to foster a deeper understanding of the role of transport in economic growth, environmental sustainability and social inclusion and to raise the public profile of transport policy.

The ITF organises global dialogue for better transport. We act as a platform for discussion and pre-negotiation of policy issues across all transport modes. We analyse trends, share knowledge and promote exchange among transport decision-makers and civil society. The ITF's Annual Summit is the world's largest gathering of transport ministers and the leading global platform for dialogue on transport policy.

The Members of the Forum are: Albania, Armenia, Argentina, Australia, Austria, Azerbaijan, Belarus, Belgium, Bosnia and Herzegovina, Bulgaria, Canada, Chile, China (People's Republic of), Croatia, Czech Republic, Denmark, Estonia, Finland, France, Former Yugoslav Republic of Macedonia, Georgia, Germany, Greece, Hungary, Iceland, India, Ireland, Israel, Italy, Japan, Kazakhstan, Korea, Latvia, Liechtenstein, Lithuania, Luxembourg, Malta, Mexico, Republic of Moldova, Montenegro, Morocco, the Netherlands, New Zealand, Norway, Poland, Portugal, Romania, Russian Federation, Serbia, Slovak Republic, Slovenia, Spain, Sweden, Switzerland, Turkey, Ukraine, the United Arab Emirates, the United Kingdom and the United States.

\author{
International Transport Forum \\ 2 rue André Pascal \\ F-75775 Paris Cedex 16 \\ contact@itf-oecd.org \\ wWw.itf-oecd.org
}

\section{ITF Discussion Papers}

ITF Discussion Papers make economic research, commissioned or carried out in-house at ITF, available to researchers and practitioners. They describe preliminary results or research in progress by the author(s) and are published to stimulate discussion on a broad range of issues on which the ITF works. Any findings, interpretations and conclusions expressed herein are those of the authors and do not necessarily reflect the views of the International Transport Forum or the OECD. Neither the OECD, ITF nor the authors guarantee the accuracy of any data or other information contained in this publication and accept no responsibility whatsoever for any consequence of their use. This document and any map included herein are without prejudice to the status of or sovereignty over any territory, to the delimitation of international frontiers and boundaries and to the name of any territory, city or area. Comments on Discussion Papers are welcome. 


\section{Acknowledgements}

The authors are grateful to the Japan International Cooperation Agency (JICA) for the provision of household travel survey data for the cities of Hanoi, Jakarta, Kuala Lumpur and Manila, and the New Zealand Ministry of Transport, National Transport Authority of Ireland, Helsinki Regional Transport Authority and the Lisbon University (SCUSSE Project) for sharing their household travel survey data for the cities of Auckland, Dublin, Helsinki and Lisbon respectively. 


\begin{abstract}
Gender is one of the key socio-demographic variables that can influence travel behaviour, but it is often the least understood. Understanding travel behaviour by gender will help better design transport policies that are efficient and equitable. Due to the gendered division of work in households, women often have multiple tasks and activities. As a result, women are more likely to have shorter commute distances, to chain trips, to have more non-work related trips, to travel at offpeak hours, and to choose more flexible modes. This study examines travel behaviour by gender in eight different cities, across three different continents, focusing on transport mode, trip purpose, travel distance and departure time for Auckland, Dublin, Hanoi, Helsinki, Jakarta, Kuala Lumpur, Lisbon and Manila. The most common trends found in the cities are that women tend to travel shorter distances and prefer public transport and taxi services to cars more than men.
\end{abstract}




\section{Table of contents}

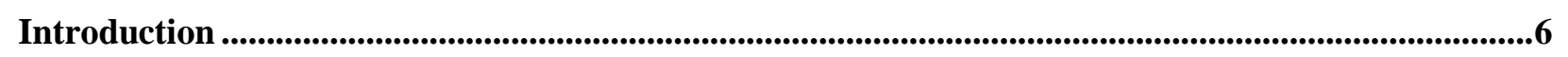

Transport and gender .........................................................................................................................................

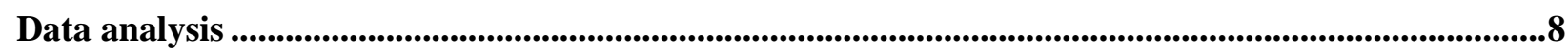

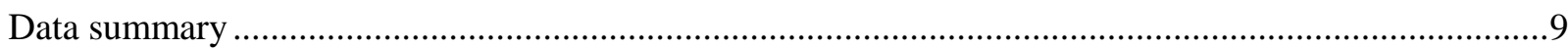

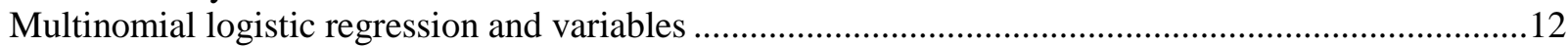

Gender differences in travel behaviour ...........................................................................................................13

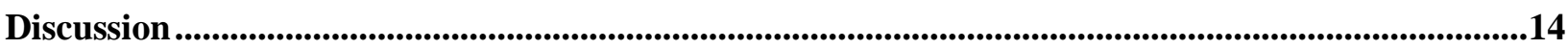

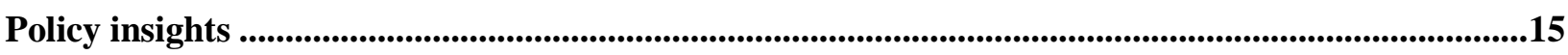

Public transport scheduling needs to consider a wider range of needs and preferences ..........................15

Taxi and informal transit services require safer regulations and technologies .....................................16

Gender analysis leads to effective and efficient transport demand management ...................................16

Safety improvements are key to ensure optimal public transport use ....................................................16

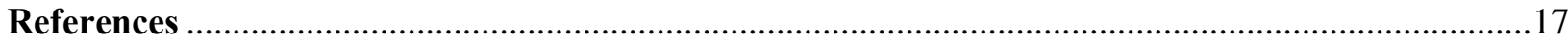

\section{Figures}

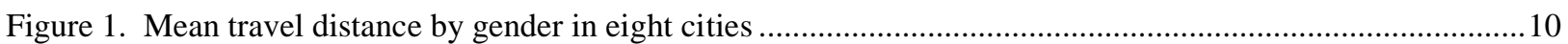

Figure 2. Distribution of departure time by gender in eight cities..................................................................11 


\section{Introduction}

A better understanding of the factors that influence individual travel behaviour can reveal changes in preferences and attitudes, provide insights to existing travel patterns, improve transport planning, prepare for future infrastructure needs and services, and help better design and implement sustainable and inclusive transport policies that will meet emissions reductions goals and improve gender equity. Transport attributes, such as travel cost and trip distance, external factors such as urban form and land use (Cervero, 2002; Giuliano, 2003; Handy et al., 2005) and socio-demographic characteristics are all critical determinants of transport mode choice. Gender, household composition, income and car ownership are the most significant socio-demographic factors in influencing travel behaviour (Best and Lanzendorf, 2005; Boarnet and Sarmiento, 1998). However, gender is often the least understood socio-demographic variable.

Since women tend to have specific travel characteristics in terms of mode choice, time of travel, trip purpose, route, trip chain and travel distance, they have very different preferences and constraints than men. For example, women have been found to make fewer journeys to work by car and more journeys for maintenance activities such as shopping and child care (Best and Lanzendorf, 2005; Boarnet and Sarmiento, 1998). Women on average also travel less often and for shorter distances than men (Moriarty and Honnery, 2005) and are more willing to reduce vehicle use than men (Polk, 2003; 2004). In addition, gender is one of the most important variables for mode choice (Bhat and Srinivasan, 2005). The differences in travel behaviour by gender are mostly due to the complexity of activities more often experienced by women than men. Due to the gendered division of work in households, women often have multiple tasks and activities, such as employment, household and caregiving responsibilities. At the same time, women's travel behaviour may be changing over time and in diverse directions between developed and developing cities.

Transport policies do not generate the same outcome for all individuals, as each individual faces a different set of constraints, which could be a result of the individual's role in the household (Sarmiento, 1996). Women and men do not usually play the same role depending on the composition of the household. Hence, policies which assume that women and men have the same travel patterns and have equal access to different modes of transport will not reach their full potential impact if they do not consider the differences in behaviour by gender. Furthermore, there may be gender bias in existing transport policies and services, as gender differences in travel behaviour is often overlooked. For example, women's use of public transport can be affected by the physical and practical considerations relating to the structural design of buses, trains and trams, yet not all design of vehicles and carriages address women's preferences or needs. Transport services that provide equal benefits across genders can only be provided if there is a better understanding of the needs of all users.

Therefore, in order to implement efficient and equitable transport policies that will benefit all users, reduce gender bias and improve existing transport services for women, gender analysis needs to be incorporated in transport planning and policy making processes. This study has selected eight cities for a comparative analysis on travel behaviour by gender. Household travel survey data were used to study transport mode, trip purpose, travel distance, and other unique transport characteristics in Auckland, Dublin, Hanoi, Helsinki, Jakarta, Kuala Lumpur, Lisbon and Manila. The listed transport variables were used to examine gender differences that cannot be explained by income or age. These cities have a wide range of existing transport services and are at different levels of economic development, which could lead to different travel behaviour, preferences and constraints. In addition, since gender differences in travel patterns are often linked to employment status, household structure, child care and maintenance tasks, cities with different gender and societal norms are likely to show varying levels of gender 
differences. This study will examine how travel behaviour varies by gender across the eight selected cities, given their differences.

\section{Transport and gender}

Travel behaviour studies conducted over the past four decades have established several trends on the distinctly different travel patterns by gender. Most studies have focused on gender transport differences in the areas of transport mode, time of travel, trip purpose, route, trip chain and travel distance. Women were found to have shorter commute distances since the 1970s (Beckmann, 1974; White, 1977; Gossen and Purvis, 2004) (and hence shorter travel time), to chain trips (Levinson and Kumar, 1995; McGuckin and Murakami, 1999), to have more non-work related trips, to travel at off-peak hours, and to choose more flexible modes, depending on other social characteristics, such as age, income, household size or number of dependents.

Such differences are mostly due to the complexity of activities more often experienced by women than men, as well as the availability of jobs closer to home (Wachs, 1998) and women's tendency to minimise work-related travel time in order to maximise the time for non-work related trips and activities (Gordon et al., 1989). This is especially true for married women and women with children. In the 2001 United States National Household Travel Survey, it was found that women make 77\% more trips per day with their children than men (NHTS, 2001). The presence of young children in a household affects women's travel patterns more than men's (McGuckin and Nakamoto, 2004), in terms of both travel distance to work and trip chaining. Women are twice as likely as men to drop off or pick up children in two-worker households and thus, have less flexible departure time than men (McGuckin and Nakamoto, 2004). Women tend to make more family and household-related trips (Rosenbloom, 1987) and have more diverse activities in both space and time. As a result, trip chaining on the way to and from work occurs more frequently for women than for men (McGuckin and Murakami, 1999; Strathman and Dueker, 1995; Al-Kazily et al., 1995; Wegmann and Jang, 1998) and could also lead to a greater preference for car use as it is a more flexible mode that can perform complex spatial-temporal transport activity patterns.

Travel behaviour trends of men and women could slowly converge as more women are entering the workforce, obtaining higher education and advancing in their respective fields in both developed and developing countries. Indeed, recent studies have shown that younger women are travelling further as they age and men are driving less (Tilley and Houston, 2016; Kuhnimhof et al., 2012). Conversely, in some cities, despite the high participation of women in the workforce and women surpassing men in higher education, the average trip for women still differs significantly from that of men (Crane, 2007). Most of these studies are focused on global metropolitan areas in developed countries. Although travel behaviour may be changing for both men and women, the gender gap in developing cities is still significant and requires greater understanding for more equitable policy implementations.

Developing cities may have different transport services and different levels of gender equity compared to those of developed cities, but similar trends have been observed. For example, women in Hanoi tend to do more trip chaining than men and they also travel more at off-peak hours (Levy, 2013), they walk more than men and tend to make more shopping trips; they are also much more likely to be motorcycle or car passengers (Tran and Schlyter, 2010). Similar to women in developed cities, women in Hanoi prefer flexible modes due to their domestic responsibilities (Bray and Holyoak, 2015) but in their 
case, they would choose motorcycles rather than cars as most families cannot afford a car and motorcycles give women the freedom of mobility they desire. Women in Hanoi were also found to be more likely than men to switch from using motorcycles to using public transport, which could have major implications on future sustainable transport policies and the development of public transport systems in Hanoi, particularly in light of the rapidly growing private vehicle market. Similarly, in Kuala Lumpur, women were found to be 2.6 times more likely to use public transport rather than a car as compared to men (Nurdden et al., 2007).

Despite the fact that women tend to use more public transport than men, public transport services in most cities are still unsafe or perceived to be unsafe. The strongest deterrent for women choosing public transport is the lack of safety. There have been recent studies in Hanoi, Jakarta and Kuala Lumpur that provide quantifiable evidence of women being much more likely than men to use public transport (Bray and Holyoak, 2015; Tjeendra et al., 2010; Nurdden et al., 2007). These studies also showed that in Hanoi and Jakarta, safety was the top priority insisted upon by women as a condition for their use of public transport (Bray and Holyoak 2015; Tjeendra et al., 2010). In addition, nearly $90 \%$ of women found the safety of trains to be poor or very poor, whereas only $35 \%$ of men held a similar concern for security in Jakarta (Turner, 2013). Furthermore, sexual harassment towards women, whether they are walking on the streets, taking buses or riding trains, has been noted as a common problem (Herrera, 2007). In Manila and Jakarta, the cases of sexual harassment reported by women using public transport are seen as a problem linked to the conditions of over-crowding and the actions taken to prevent such occurrences remain categorised as responses to the volume of passengers (Herrera, 2007). Interviews with transport professionals in these regions revealed a lack of awareness of the social and gender implications for transport policies, influenced by culturally learned discriminatory gender norms, such as the taboo of speaking about sexual harassment (Herrera, 2007). Such discriminations have resulted in women travelling primarily at certain hours of the day and often with a companion to insure their own safety (Herrera, 2007).

Policies with the objective of switching to more sustainable modes of transport would first need to address the different characteristics and preferences of transport users that could be highly distinctive between genders. Without understanding how women's travel behaviour varies from men's, it will be challenging to design and implement efficient and equitable transport policies.

\section{Data analysis}

Multinomial logistic regression analysis is performed in this study to estimate the effect of gender, age, household income, number of household members, trip purpose, travel distance and departure time on primary mode choice. This method uses a logistic distribution and the method of maximum likelihood for estimating the coefficients (Hosmer and Lemeshow, 2000) and McFadden's pseudo coefficient of determination was used to assess the quality of the models (McFadden, 1974). Although there are many other significant factors that could influence mode choice, such as vehicle ownership and availability of a valid driver license, they are unavailable for all the eight cities included in the analysis.

In this study, primary mode choice is defined as the transport mode used to travel the longest distance. A separate model was constructed for each of the eight cities using household travel survey data collected by the Japan International Cooperation Agency (JICA) for Hanoi (2005, n = 187 793), Jakarta (2000, $\mathrm{n}=1083$ 275), Kuala Lumpur (1999, $\mathrm{n}=218$ 447), and Manila (1996, $\mathrm{n}=468$ 249) and from 
household travel surveys conducted by the New Zealand Ministry of Transport, National Transport Authority of Ireland, Helsinki Regional Transport Authority and the Lisbon University (SCUSSE Project) for the cities of Auckland (2013, $\mathrm{n}=20$ 130), Dublin (2012, $\mathrm{n}=9$ 578), Helsinki (2012, $\mathrm{n}=$ 8 063), and Lisbon (2013, $n=2940$ ) respectively. These cities were selected because of their diversity in terms of population size, economic development, transport infrastructure and services, and mode choice. This study seeks to explore how gender could affect travel behaviour in similar ways despite such differences across cities. Since all the eight travel surveys were conducted in different years, ranging from 1996 (Manila) to 2013 (Auckland), and updated data for the developing Asian cities were unavailable, there is a limitation to the comparison of behaviour across the different cities. However, the data can nevertheless provide insights on transport gender behaviour within each city and observations on general trends as shown in the following sections.

\section{Data summary}

Cross tabulation results and descriptive statistics provide a preliminary overview of general behaviour trends on mode choice, trip purpose, mean travel distance, and departure time. These results show that more commuting trips are made by men than women in most cities. Men dominate the use of cars as their primary mode choice by approximately double that of women in the four Southeast Asian cities, but there is no major difference in developed cities except in Helsinki, where the private vehicle mode share for men is $17 \%$ higher than for women. However, it is important to note that the mode share for cars is relatively lower in the Southeast Asian cities. Auckland and Dublin show a high level of equity between the genders with regards to transport mode choice. The other six cities however, tend to show men making more trips by car or motorcycle and women making more trips by buses or nonmotorised modes. In fact, Dublin and Lisbon are the only two cities where there is a slightly higher nonmotorised mode share (walking and bicycle) for men than women. Despite the small taxi share in almost all cities, women choose to use taxi services more than men in Helsinki, Jakarta, Lisbon, and Manila. These trends are aligned with studies that have shown that women prefer more flexible modes (Bray and Holyoak, 2015). In Dublin, Hanoi and Helsinki, there are no significant differences between commuting patterns of men and women. However, as might be expected given the ubiquitous trends of the distribution of domestic responsibilities, the other six cities show without exception that men are making more commute trips and women are making more non-commute trips. Lastly, the average distance men travel is notably higher than that of women in all cities (40\% higher in Southeast Asian cities on average, mainly due to Jakarta; less than $10 \%$ in other cities) (Figure 1) and more women than men travel during off-peak hours (Figure 2). 


\section{Figure 1. Mean travel distance by gender in eight cities}

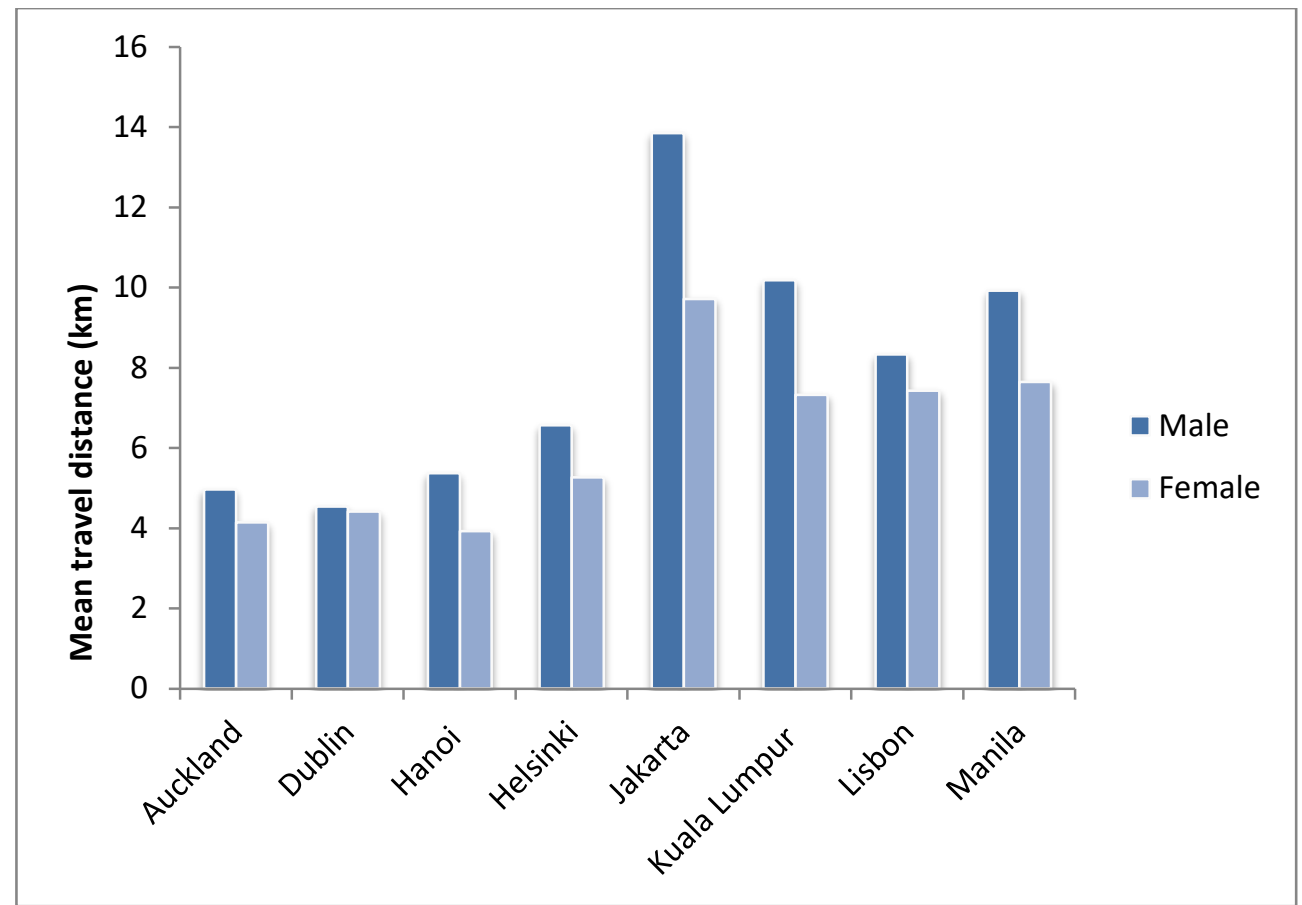


Figure 2. Distribution of departure time by gender in eight cities
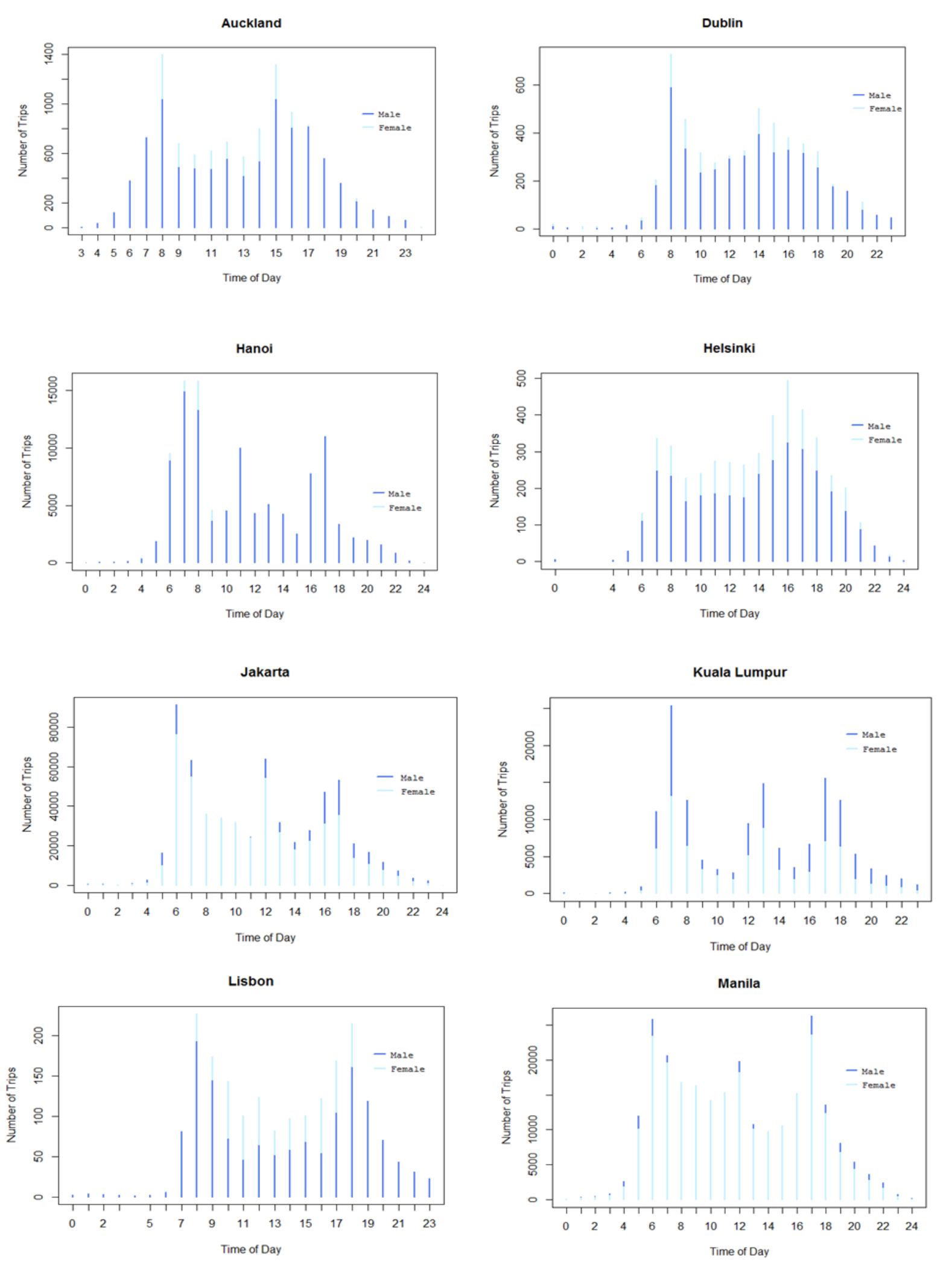


\section{Multinomial logistic regression and variables}

In order to compare the gender differences in transport behaviour with those of income and age, these three socio-demographic variables, together with four other key control variables were included in the same multinomial logistic regression model for each city. Transport mode is the dependent variable in all eight regression models as shown in Equation (1), which is an example for the bus mode in Auckland.

$$
\begin{aligned}
Y_{\text {Bus }}=\alpha_{\text {Bus }} & +\beta_{\text {Gender Gender }}+\beta_{\text {Age }} \text { Age }+\beta_{\text {Household Income Household Income }} \\
& +\beta_{\text {Trip Purpose Trip Purpose }}+\beta_{\text {Travel Distance Travel Distance }} \\
& +\beta_{\text {Departure Time }} \text { Departure Time }
\end{aligned}
$$

where $Y$ is the dependent variable, $\alpha$ is the $\mathrm{Y}$-intercept and $\beta$ is the estimate of the regression slope.

The reference mode for Auckland, Dublin, Helsinki and Lisbon is always private vehicle, which includes both light-duty vehicles and motorcycles, since this is usually the category with the greatest number of trips. Such a reference mode will also allow the comparison of a more flexible form of transport to more structured transport systems. The reference mode for Hanoi, Jakarta, Kuala Lumpur and Manila is motorcycle due to its relatively high share in these cities.

\section{Mode choice}

Transport mode choice for each city was recoded from the original data to present a consistent set of alternatives that is comparable for all eight cities and contains walking and bicycle, private vehicle (i.e. light-duty vehicles including car and light trucks), motorcycle, bus, train and taxi. In Hanoi, Jakarta, Kuala Lumpur and Manila, motorcycle is a separate choice from light-duty vehicle, while in the other four cities, these two modes were combined into one. This was mostly due to the relatively low number of motorcycle trips in Auckland, Dublin, Helsinki and Lisbon.

Train includes metro, light rail and commuter rail where applicable, and in the case of Lisbon, it also includes ferry due to the manner in which the original data were collected. The bus mode includes trams (Lisbon only) and small buses (Hanoi, Jakarta, Kuala Lumpur and Manila), i.e. informal transit in cities with such services. Bus and train are separate alternatives for all cities since they tend to reflect different gender preferences. On the other hand, walking and bicycle have been grouped together, as both are forms of non-motorised transport. Where applicable, three-wheelers were grouped with the taxi mode due to their common flexibility characteristic.

\section{Trip purpose}

Trip purpose data were divided into commute, non-commute and home trips for the purpose of the regression analysis. Commute trips only contain "work trip" and all other trips were categorised as non-commute, with the exception of home trips, which was kept separate. The original data had a wider range of choices, with Helsinki having as many as 20 trip purpose types for example.

\section{Socio-demographic variables}

In addition to gender, age and income, the number of household members is also included in the regression models with the objective of estimating the impact of the number of dependents (e.g. young children or elderly adults) on transport mode choice. This variable is only included in the regression models for Hanoi, Jakarta, Kuala Lumpur and Manila due to the lack of data in the other four cities. 
Hence, in addition to the six variables shown in Equation (1), household member is an additional variable for these four cities.

\section{Gender differences in travel behaviour}

The results from the multinomial logistic regression analysis conducted for each city, which include adjusted odds ratios for the independent variables, are discussed in this section. Odd ratios are estimated as they are one of the most intuitive measures used to understand the relationship between the covariates and the outcome variable in this case (Hosmer and Lemeshow, 2000). With regards to the quality of the models, the pseudo-R2 levels were relatively substantial for most cities $(0.26-0.74)$, with the exception of Dublin (0.16) and Auckland (0.19), giving potential evidence of missing variables from these two models that have an influence on mode choice.

Gender is highly significant $(\mathrm{p}<0.01)$ for almost all modes in cities. The only exception is with regards to taxi in Dublin, which is only represented by a small mode share (48 trips). Age and income are also very significant $(\mathrm{p}<0.01)$ for nearly all transport modes in Auckland, Helsinki, Jakarta, Kuala Lumpur and Manila. On the other hand, these two covariates are insignificant for all modes in Dublin except walking/bicycle with regards to income. Furthermore, in Hanoi, income is insignificant for bus and taxi and in Lisbon, it is insignificant for train, while age is insignificant for walking/bicycle and bus. Thus, gender is found to be much more significant for more transport modes consistently than age and income. Lastly, the transport variables of trip purpose, travel distance and departure time were very significant $(p<0.10-p<0.01)$ in most of the cities, giving further evidence of the important role they play in determining mode choice.

In two of the developed economies and in all of the four Southeast Asian cities, the regression models show women preferring alternative transport modes, such as trains, buses, taxis and walking/bicycle, over private vehicles. In particular, women in Helsinki are 2.6 times more likely than men to take a taxi instead of a car/motorcycle, 2.4 times more likely to ride a bus, over twice more likely to ride a train, and 1.7 times more likely to walk or bicycle. These trends of sustainable transport behaviour among women echo Polk's findings in Sweden (Polk, 2003). Similarly, women in Lisbon are 2.6 times more likely than men to choose a taxi over a private vehicle, 2.2 times more likely to choose a bus or tram and 1.3 times more likely to choose a train.

In the four Southeast Asian cities, since motorcycle is the dominant mode of transport, this was the reference used to quantify mode preferences. Beginning with Jakarta, women are 2.3 times more likely than men to choose a taxi over a motorcycle, a figure which drops to 1.9 for buses, 1.7 for non-motorised and other modes, 1.5 for train, and 1.3 for cars. This trend is even stronger in Kuala Lumpur, where women are an astounding 7.6 times more likely than men to choose a taxi instead of a motorcycle, a figure that drops to 4.8 for train, 4.5 for bus, 3.5 for walking/bicycle, and 3.0 for car or other modes. Similarly, in Manila, women are 3.9 times more likely than men to prefer a bus to a motorcycle, 3.8 times more likely to prefer a taxi or train, 3.4 times more likely to prefer walking or cycling, and twice more likely to prefer driving a car.

Given the small but rapidly growing population of car owners in Vietnam, it is important to note that in its capital Hanoi, men are 2.3 times more likely to choose a car over a motorcycle than women. Hanoi is the only city in which men prefer cars to motorcycles more than women, although the relatively small 
number of trips by car ( $\mathrm{n}=1435$ out of a total of 187793 trips) in this city limits the significance of the finding. Conversely, women are 2.3 times more likely than men to choose walking or cycling over a motorcycle, and respectively 1.4 and 1.3 times more likely to choose a bus or a taxi.

Auckland and Dublin differ from these trends with regards to certain transport modes. In particular, while women are 1.4 times more likely than men to prefer a train to a private vehicle in Auckland, they are also two times less likely to choose a bus over car and 1.3 times less likely to choose walking or bicycling. Similarly, Dublin women are 1.6 times more likely to choose a train over a private vehicle compared to men, but they are 1.3 times less likely to take a bus, or to walk or bicycle.

It has already been stated that income and age are very significant $(\mathrm{p}<0.01)$ explanatory variables across the board. In particular, people who are older tend to prefer driving private vehicles to buses and to prefer taxis more than private vehicles. Additionally, in all cities except Manila, household income tends to have a neutral or slight positive correlation with choosing a train over a private vehicle. All other trends vary greatly between modes and geographic regions.

Lastly, the coefficient for the number of household members, a variable only present in the Southeast Asian city models due to availability issues. For both genders in Jakarta, having more household members is positively correlated to choosing to ride a bus, a taxi or walking/bicycling over using a motorcycle. The number of household members is also significant for all modes in Hanoi, with a larger household leading to a higher frequency of trips by taxi and walking/bicycling and a lower frequency by car or bus as compared to by motorcycle. Kuala Lumpur has significant coefficients for household members for all modes except train and other modes. Additionally, women are more likely to choose a train over a motorcycle as the household grows $(1.05, \mathrm{p}<0.10)$, whereas for men there is no statistically significant difference. In Manila, the number of household members does not have an important influence on mode choice for women, but it does for certain modes among men, who tend to choose a taxi or walking/bicycling over a motorcycle when there are more members $(1.04, \mathrm{p}<0.01$; $1.08, \mathrm{p}<0.01)$.

\section{Discussion}

Gender remains a significant determinant of transport mode choice across the eight selected cities in this study, regardless of their status of economic development and other differences, even though the same trends may not always hold true for every city. Gender is a more robust determinant of mode choice than age or income. Women prefer public transport modes, such as bus or train, over driving a car in all cities selected in this study, except in Dublin and Auckland. Women in all cities except Dublin prefer riding a taxi over using a private vehicle (car or motorcycle) more than men. Since women have more complicated travel patterns, they tend to prefer more flexible modes, such as taxi, but at the same time, public transport modes are more appealing to them than to men. These findings imply that flexible modes, especially emerging trends such as shared mobility or mobility as a service, could attract more female than male users and when given better alternatives, women may be ready to give up driving altogether. If cities want to further encourage the development of such flexible modes, policies that will address women users' preferences should be implemented as women will be the dominating users. Similarly, although women prefer to use public transport modes more than men, most of the cities included in this study do not have transport programmes or policies that are focused on improving the 
user experience of women transit riders considering their off-peak time of travel and non-commute trip purpose.

Travel distance per trip is also higher for men than women, which is a persistent trend across all eight cities. Hence, some characteristics, such as housing and job location choice and the value of time for non-work related trips and activities, may be gender specific and not unique to city type, geographical location, or level of economic development. Shorter travel distance could also make women an attractive target market for shared mobility services. Among the four cities where motorcycle and car were analysed separately, women in Jakarta, Kuala Lumpur and Manila prefer cars over motorcycles more than men do. This could suggest a continuous increase in private vehicle use in these three cities, especially as these economies grow and household income rises, allowing more women to be able to afford their preferred mode of transport. Hence, these cities may need to conduct more detailed gender analysis in order to prevent further increases in private car use and to design more sustainable transport alternatives.

\section{Policy insights}

This study has shown that women transport users have more similar travel characteristics to other women in different cities than with men in their own cities, supporting the fact that gender plays a more substantial role in affecting travel behaviour than other factors, such as the built environment, existing transport services, or even age and income. For example, travel distance is found to be longer for men than women across all eight cities, where men also make more commuting than non-commuting trips, drive more (especially in developing cities) and travel more during conventional peak hours that reflect regular working hours. It is clear that in order to implement efficient and equitable transport policies, the differences in travel behaviour by gender have to be considered and addressed accordingly in both developing and developed cities. Although it is imperative that the gender mainstreaming of transport policies and programmes take place at every level to achieve true gender equity, four main policy insights have been identified in this study.

\section{Public transport scheduling needs to consider a wider range of needs and preferences}

Women tend to have more complicated schedules that often include more trips per day and consist of more than two points of origin and destination. Hence, this could explain why men tend to have more commuting trips, whereas women travel more for non-commuting trips, as commuting trips are just one type of the various kinds of trips they make in a day. This also implies that women tend to link multiple trips more than men. However, public transport, which more women use than men, makes trip chaining a challenge due to increases in travel time and cost. In addition, the fact that women tend to travel more before peak hours both in the morning and afternoon imply that their work schedules and time of travel are different from those of men, who may have more regular and fixed working hours. Therefore, if public transport services are to be gender neutral or have a higher level of gender equity, it is necessary to schedule them according to a wider range of travelling and working hours. Improvement of public transport services should thus include changes in the scheduling of buses or trains and the synchronisation of their arrival and departure time to address the needs of all users, in addition to any physical or structural modifications in public transport planning and design. 


\section{Taxi and informal transit services require safer regulations and technologies}

Flexible transport modes, such as taxi and informal transit services are more attractive to women than men in most cities. Although ride sharing services are not included in this study, it is expected that women will be a larger user group of such services, due to their stronger preference for flexible modes (as compared to private vehicle use) than men, especially in developing cities. However, women's safety when using such modes has not been a priority concern in most cities. Specific regulations, such as careful driver profiling, sharing of vehicle information and expected time of arrival, provision of emergency alert features, hiring and training of women drivers, greater co-ordination with the police, and increasing commuter education and awareness can all increase the safety of taxi, informal transit and ride sharing services. Some of these regulations can be easily and cost efficiently implemented and enforced with the use of technology in the form of apps and GPS tracking. As door-to-door transport services that will improve personal mobility continue to grow in different cities across the world, they need to be safe transport options for all users regardless of gender.

\section{Gender analysis leads to effective and efficient transport demand management}

The differences in travel behaviour by gender will influence the efficiency and effectiveness of transport demand management strategies, such as fiscal policies including road and parking pricing, fuel tax and public transport fare subsidies, or programmes that will promote non-motorised transport. For example, as women's travel distances are shorter than those of men, their transport behaviour will be less affected by variable pricing policies that depend on travel distance than fixed pricing, such as cordon pricing in the case of congestion pricing. Variable pricing policies can therefore be more equitable for women in general. Since women also drive less in general, though not in all cities, their travel behaviour will be more affected by transport demand management strategies that are focused on the improvement of public transport services or non-motorised modes and public transport fare subsidies. On the other hand, for women who drive and make more trips in a day, they are subject to more parking fees than men with only commuting trips. Not all transport demand management strategies will be appropriate for women due to their distinct travel behaviour. In addition, women can also be affected differently by various incentive programmes, such as employer based transit subsidies or the provision of shuttle services after regular working hours. Hence, gender analysis should be integrated into the design and implementation of transport demand management strategies that will allow greater levels of flexibility and consideration of all users.

\section{Safety improvements are key to ensure optimal public transport use}

This study has shown that women travel shorter trips on average than men, which can be easily facilitated by public transport services if they are available. This could explain why women have stronger preferences to use public transport modes than men in most of the cities included in this study. However, women also make more non-commuting trips and travel more during off-peak hours, which imply that public transport services may not be readily available when required by women users and such services may also not be provided under the safest circumstances, especially during off-peak hours. Safety is a concern that affects women's transport behaviour across all transport modes more than men in general. If cities want to increase their public transport use and occupancy rates, the safety of their services have to be considered in order to attract more women passengers and also to improve the experience of the substantial share of existing women users. This is especially critical in developing cities, where efficient, equitable and safe public transport modes play an important role in regulating the growing share of private vehicle use, including motorcycles. Motorisation will continue to increase in developing cities. However, in order to encourage a shift from being a potential driver to a public transport user, adequate and safe public transport needs to be a viable option. Policies that will contribute to the development of 
safe public transport services will also contribute to a city's and country's overall climate change mitigation measures. Some examples of safety measures for public transport include reservation of women-only coaches, operation of women-only buses, separated sections and reserved seats for women in buses, installation of camera and GPS tracking, well-lit bus stops and interchanges, and minimising of crowding during boarding and alighting.

\section{References}

Al-Kazily, J., Barnes, C. and Coontz, N. (1995), "Household Structure and Travel Behavior", 1990 NPTS Demographic Special Reports, FHWA, United States Department of Transportation.

Beckmann, M. (1974), "Spatial equilibrium in the housing market”, Journal of Urban Economics, Vol. 1/1, pp. 99-107.

Best, H. and Lanzendorf, M. (2005), "Division of labour and gender differences in metropolitan car use: An empirical study in Cologne, Germany", Journal of Transport Geography, Vol. 13/2, pp. 109121.

Bhat, C.R. and S. Srinivasan (2005), "A multidimensional mixed ordered-response model for analyzing weekend activity participation”, Transportation Research Part B: Methodological, Vol. 39/3, pp. 255-278.

Boarnet, M.G. and S. Sarmiento (1998), "Can land-use policy really affect travel behaviour? A study of the link between non-work travel and land-use characteristics", Urban Studies, Vol. 35/7, pp. 1155-1169.

Bray, D. and N. Holyoak (2015), "Motorcycles in Developing Asian Cities: A Case Study of Hanoi”, $37^{\text {th }}$ Australasian Transport Research Forum, unpublished conference paper.

Cervero, R. (2002), "Built environments and mode choice: Toward a normative framework", Transportation Research Part D: Transport and Environment, Vol. 7/4, pp. 265-284.

Crane, R. (2007), "Is there a quiet revolution in women's travel? Revisiting the gender gap in commuting", Journal of the American Planning Association, Vol. 73/3, pp. 298-316.

Giuliano, G. (2003), "Travel, location and race/ethnicity", Transportation Research Part A: Policy and Practice, Vol. 37/4, pp. 351-372.

Gordon, P., A. Kumar and H. Richardson (1989), "Gender differences in metropolitan travel behaviour", Regional Studies, Vol. 23/6, pp. 499-510.

Gossen, R. and C.L. Purvis (2004), "Activities, Time, and Travel”, Research on Women's Issues in Transportation 21, Transportation Research Board of the National Academies.

Handy, S., X. Cao and P. Mokhtarian (2005), "Correlation or causality between the built environment and travel behavior? Evidence from Northern California", Transportation Research Part D: Transport and Environment, Vol. 10/6, pp. 427-444.

Herrera, M. (2007), "Sexual harassment in public transport: An exploratory study using a gender and development perspective", Unpublished Master of Arts Dissertation, University of the Philippines, Diliman, Quezon City. 
$\mathrm{Ng}$ and Acker - Understanding Urban Travel Behaviour by Gender for Efficient and Equitable Transport Policies

Hosmer, D.W. and S. Lemeshow (2000), “Applied Logistic Regression”, John Wiley \& Sons, Inc, $2^{\text {nd }}$ Edition, New York.

Kuhnimhof, T., J. Armoogum, R. Buehler, J. Dargay, J.M. Denstadli, and T. Yamamoto (2012), "Men shape a downward trend in car use among young adults: Evidence from six industrialized countries", Transport Reviews, Vol. 32/6, pp. 761-779.

Levinson, D. and A. Kumar (1995), "Activity, travel, and the allocation of time", Journal of the American Planning Association, Vol. 61/4, pp. 458-470.

Levy, C. (2013), "Travel choice reframed: Deep distribution and gender in urban transport", International Institute for Environment and Development, Vol. 25/1, pp. 47-63.

McFadden, D. (1974), "Conditional Logit Analysis of Qualitative Choice Behavior", in P. Zarembka (ed.), Frontiers in Econometrics, Academic Press.

McGuckin, N, and E. Murakami (1999), "Examining trip-chaining behavior: Comparison of travel by men and women", Transportation Research Record, Vol. 1693, pp. 79-85.

McGuckin, N. and Y. Nakamoto (2004), "Differences in Trip Chaining by Men and Women", Conference Proceedings 35: Research on Women's Issues in Transportation, Volume 2: Technical papers, Transportation Research Board of the National Academies.

Moriarty, P. and D. Honnery (2005), "Determinants of Urban Travel in Australia", $28^{\text {th }}$ Australasian Transport Research Forum (ATRF).

NHTS (2001), "National Household Travel Survey 2001”, United States Department of Transportation Federal Highway Administration.

Nurdden, A., R. Rahmat and A. Ismail (2007), "Effect of transportation policies on modal shift from private car to public transport in Malaysia", Journal of Applied Sciences, Vol. 7/7, pp. 1014-1018.

Polk, M. (2003), "Are women potentially more accommodating than men to a sustainable transportation system in Sweden?" Transportation Research Part D: Transport and Environment, Vol. 8/2, pp. 75-95.

Polk, M. (2004), "The influence of gender on daily car use and on willingness to reduce car use in Sweden", Journal of Transport Geography, Vol. 12/3, pp. 185-195.

Rosenbloom, S. (1987), "Impact of growing children on their parents' travel behavior: A comparative analysis", Transportation Research Record, Vol. 1135, pp. 17-25.

Sarmiento, S. (1996), "Household, Gender, and Travel”, Women's Travel Issues: Proceedings from the Second National Conference, United States Department of Transportation Federal Highway Administration.

Strathman, J. and K. Dueker (1995), "Understanding Trip Chaining", 1990 NPTS Special Reports on Trip and Vehicle Attributes, FHWA, United States Department of Transportation.

Tilley, S. and D. Houston (2016), "The gender turnaround: Young women now travelling more than young men”, Journal of Transport Geography, Vol. 54, pp. 349-358.

Tjeendra, M., T.B. Joewono and D.U. Ningtyas (2010), "Perceptions and Experiences Regarding Service Quality in Indonesian Public Transport based on Gender", $12^{\text {th }}$ World Conference on Transport Research, Lisbon, Portugal, 11-15 July 2010, Unpublished Conference Paper.

Tran, H.A. and A. Schlyter (2010), "Gender and class in urban transport: The cases of Xian and Hanoi", Environment and Urbanization, Vol. 22/1, pp. 139-155. 
Turner, J. (2013), "Urban Mass Transit and Social Sustainability in Jakarta, Indonesia". Global Report on Human Settlements 2013, UN-HABITAT. http://www.unhabitat.org/grhs/2013 (accessed 28 June 2017).

Wachs, M. (1998), “The Automobile and Gender", Women's Travel Issues: Proceedings from the Second National Conference, United States Department of Transportation Federal Highway Administration.

Wegmann, F.J. and T.Y. Jang (1998), “Trip linkage patterns for workers”, Journal of Transportation Engineering, May-June.

White, M.J. (1977), "A model of residential location choice and commuting by men and women workers", Journal of Regional Science, Vol. 17, pp. 41-52. 
